\title{
Runway Excursions: Bearing Strength Control of Unpaved Areas
}

\author{
L. Cicmanec ${ }^{1 *}$ and O. Ulrich ${ }^{2}$ \\ ${ }^{1}$ Faculty of Military Technology, University of Defence, Czech Republic \\ ${ }^{2} 24^{\text {th }}$ Air Transportation Base at Prague, Czech Air Force, Czech Republic
}

The manuscript was received on 1 July 2020 and was accepted after revision for publication as research paper on 15 June 2021.

\begin{abstract}
:
The paper deals with the Dynamic Cone Penetrometer application which is intended to work as a vital means to support the bearing strength evaluation over the vast unpaved airport areas. Having identified fundamental drawbacks, the authors proposed some refinements in the original methodology. These predominantly respect the needs of airport operation services. Specifically, the model based on fuzzy logic and two tables, exceptionally suitable for day-to-day applications, are proposed and tested upon the extensive data set acquired at four airports over the last four years.
\end{abstract}

\section{Keywords:}

aircraft, airport, bearing strength of soils, runway, runway excursion

\section{Introduction}

As the new quality measures comprising adhesion control are introduced at airports, the air traffic at airports may be safer. However, the conditions for runway excursions are still in place. Even statistical surveys of severe aircraft incidents and accidents in the European Union, as well as across the globe display that the majority of accidents involve aircraft runoff or undershoots $[1,2]$. Since the runway excursion incidents cannot be fully eliminated, the outcomes can be mitigated through a precise and thorough design and quality check of adjacent unpaved areas to paved runways. Not only should the area be free from obstructions, but the unpaved, often unprepared surfaces should also provide sufficient drag to stop an aircraft within a designated area. At the same time, the aircraft wheel roots should be shallow enough not to pose any risk to aircraft damaging [3,4]. The surface design is dependent on numerous soil character-

\footnotetext{
* Corresponding author: Air Force Department, Faculty of Military Technology, University of Defence, Kounicova 156/65, CZ-662 10 Brno, Czech Republic. Phone: +420 6044692 51, E-mail:ludek.cicmanec@unob.cz.ORCID0000-0003-4730-6157.
} 
istics comprising predominantly soil composition and moisture content being highly subjective to changing meteorological conditions. Nevertheless, the mentioned properties can only be retained by appropriate monitoring containing a constant bearing strength assessment of these areas. It is supposed to be adjusted to aircraft operated at a particular airport. Ranieri proposes the bearing strength equalling 17, 16, and $15 \mathrm{CBR}$ at three areas along a runway $(30-50 \mathrm{~m}, 50-65 \mathrm{~m}$, and $65-105 \mathrm{~m}$ distant from the runway centreline) [5]. Generally, it is believed that the inspection is due to be conducted with the aid of penetrometers, which provide the best overview of the bearing strength. Although the penetrometers are fitted with sophisticated scales and with data-logging features, the application methodology is obstructive, complicated, elaborate, and time-consuming. So the following text tackles the possible simplification of the application methodology for quick deployment at airfields by the Dynamic Cone Penetrometer (DCP).

\section{Methods}

\subsection{Dynamic Cone Penetrometer versus Airfield Dynamic Penetrometer}

In the 1960s, new jet-propelled, tactical, and transport aircraft were introduced in Czech military aviation. For tactical reasons, the operations were to be retained from the airfield network comprising both paved and unpaved runways. To assess the bearing capacity of unpaved runways, new procedures which involved a device called the Airfield Dynamic Penetrometer (ADP) were developed. The device has been applied ever since. It is characterized by a simplistic design, uncomplicated handling, and applicability in a wide range of soil conditions. In the beginning, the application methodology was extremely flexible. The personnel was able to adjust measurements to a local soil condition. However, as time passed, the lessons were learned to reveal the unwanted spacious dispersion of measured strength values. It was rather considerable in the depth of $30 \mathrm{~cm}$. It was learned that the device generates an excess of errors which supported doubts over the rationality of the fine adjustment to slightly different soil conditions distinguishing all airports. As a result, an optimized, universal formula for prevailing soil conditions and a matrix for a quick field application at airfields were introduced.

The current ADP application can be easily formalized by minimalistic procedures and quick deployment, applicable even by non-professionals, in the 1980s and 1990s by conscripts, untrained in both soil mechanics and the penetrometer application. Being roughly $80 \mathrm{~cm}$ long, weighing less than $3 \mathrm{~kg}$ in total, the device is well designed for a comfortable single man operation. However, it lacks the California Bearing Ratio (CBR) to define maximum ground pressure. Instead, the MPa is reported, which directly represents the contact surface pressure against the load given by an aircraft tire over a contact surface. In order to preserve this obsolete equipment for posterity, a reliable relationship between the ADP and the in-situ CBR is vital to find. An attempt to ascertain an interim relationship has already been made (see Fig. 1). However, the issued bearing strength interval was extremely limited to come with the real operational needs. On top of this, these tests were conducted in specific soil conditions, which did not provide sufficient ground for necessary generalization [6]. As already mentioned, it was perceived that the device generates its error plummeting gradually with increasing soil depth down to a maximal deviation in the depth of $30 \mathrm{~cm}$ (see Fig. 1). As there is no difference in diameter between the top and connec- 
tion rod (see Fig. 2), the rod seems to generate additional friction, which increases with the soil depth.

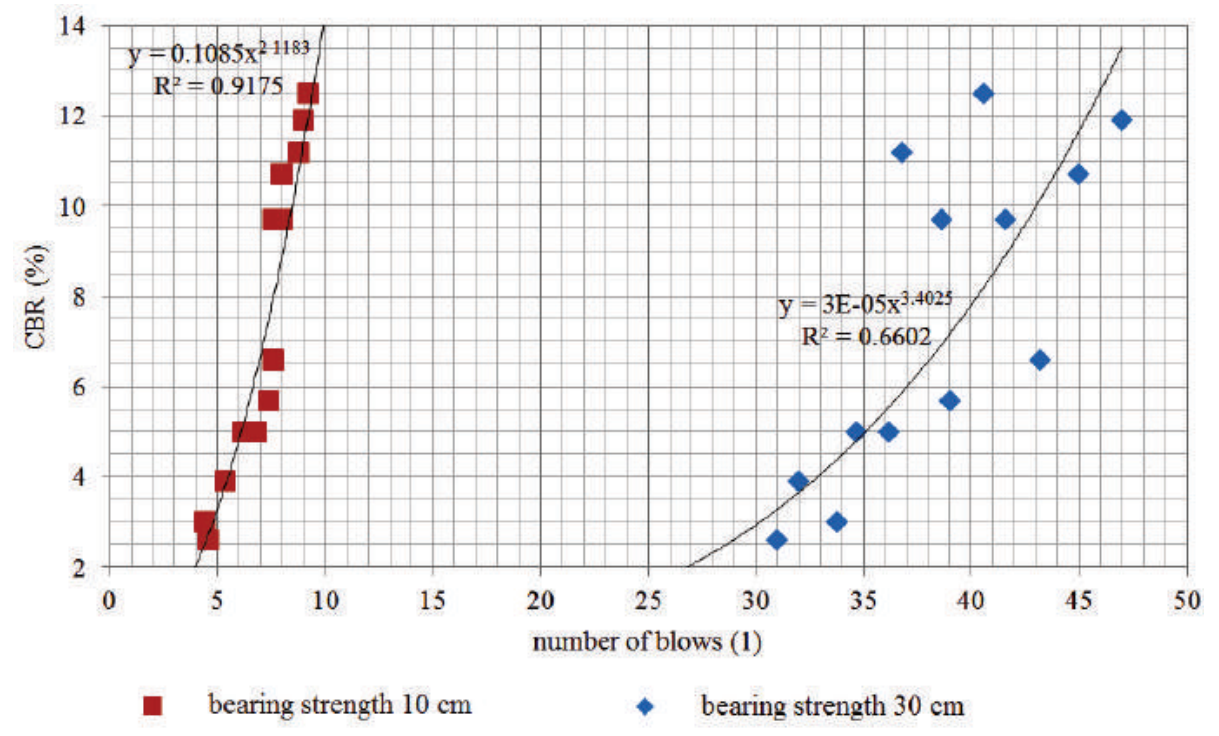

Fig. 1 Dispersion of the bearing strength by use of ADP in homogeny soil condition in depths of 10 and $30 \mathrm{~cm}$ [5]

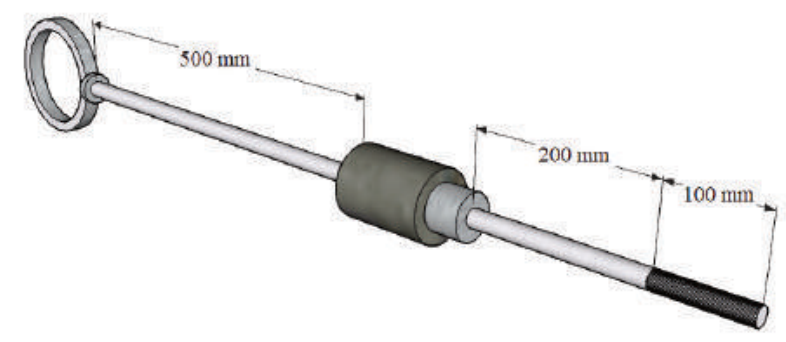

Fig. 2 Schematics of the Airfield Dynamic Penetrometer (ADP)

While seeking a solution to tackle the lack of reading in the CBR, a device working on a similar base just like the ADP, which is well correlated with the traditional CBR techniques, was pursued. The DCP was considered as a prospective substitution, and the idea was to investigate whether its operation methodology is modifiable to come with the needs of daily airport operations.

\subsection{Dynamic Cone Penetrometer a Promising Substitution to the Airfield Dynamic Penetrometer}

The DCP may be the vital and promising replacement to the obsolete ADP since it is used in many field applications with its well-supported formulas to estimate the CBR. In the following chapter, the DCP is about to be concisely investigated focusing on 
airfield operations with its highs and lows. Consequently, an outlook of methodology refinements, which may address its main drawbacks, is expected to be drafted.

Firstly, the DCP set was originally developed to assess the bearing strength of soils for building purposes. It can evaluate bearing strength in the CBR estimate. A more extensive application range, including paved roads and airfield constructions, was firstly targeted by the U.S. Corps of Engineers. They took the advantage to address the strength evaluation of unpaved, expedient, and aggregated airfields. A universal methodology, applicable elsewhere in varying soil conditions, was developed $[7,8]$.

Principally, the DCP measures the drag of the penetrating cone instigated by soil. In other words, the force induced by a falling hammer with the weight of either 8 or $4.6 \mathrm{~kg}$ is transferred through an anvil and a connecting rod to a cone tip $\left(60^{\circ}, 16 \mathrm{~mm}\right.$ diameter), which penetrates to a soil (see Fig. 3). So as to ascertain the strength measure, a rate of penetration depth and a number of blows is obtained for essential layers in a specific soil profile and reported as a DCP index [7, 9-12]. It supports a wide range of even strengths over $100 \mathrm{CBR}$. That is achieved through its design of the penetrating cone as well as the weight applied. Two weights can be selected, particularly $8 \mathrm{~kg}$ for greater soil strength ranges, whereas the 4.6 for the soft soils to tackle higher accuracy. Having learned from practical applications at airfields, the $4.6 \mathrm{~kg}$ one is sufficient. As a consequence, the following models take full advantage of this weight as well.

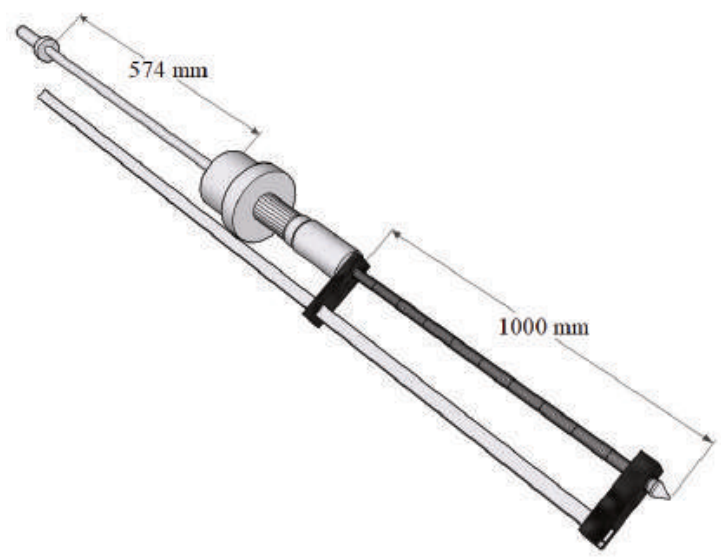

Fig. 3 Schematics of Dynamic Cone Penetrometer set (DCP set)

\subsection{Methodology of Airfield Application}

The benefit of the DCP use has been inherently realized. Above all, it supports the CBR in a considerable wide range of bearing strength, in contrast to the Airfield Cone Penetrometer (ACP), which has some limitations. The ADP can measure up to a maximum of $15 \mathrm{CBR}$, which is operationally very limiting. It is unable to penetrate through both hard crusts with coarse sands or gravel layers. On the other hand, the potential of the DCP was realized by the U.S. Corps of Engineers, who defined the procedure for an assessment of expedient and aggregated airfield surfaces. It is based on measurements down to the depth of 32 in $(812.8 \mathrm{~mm})$ with increments of roughly 2 in $(50.8 \mathrm{~mm})$. That is to obtain an overview of a strength profile at first. Then, to 
assess the soil strength, an average of the weakest layer of 12 in $(304.8 \mathrm{~mm})$ thick with the lowest strength out of the entire profile is taken. Four conditions, including the state when the strength grows gradually with a depth, the soft layer over the hard soil, the hard layer over the soft soil, and varying strengths over the entire strength profile, are distinguished in the methodology [7, 13].

This methodology is extremely efficient while providing detailed information on the soil strength properties in the entire soil strength interval. It is essential when evaluating surfaces with a hard crust in the first $100 \mathrm{~mm}$. On account of adequate dynamic forces, the device can penetrate down to a soft layer. The ability to penetrate coarse soils is specifically critical at airfields retaining the air traffic of heavy and large transport aircraft. From experience, even the strengths over $35 \mathrm{CBR}$ are vital to ascertain. Having the capacity to measure the CBR over $100 \%$ [8], the DCP set has abundant force potential to support the required strength.

Apart from the stated highs, the DCP application has its lows too. An excessive time is required for the operation. The results may be somewhat subjective, dependent upon the operating personnel giving slightly different outcomes. A relatively heavyweight design could be operationally obstructive. An airfield movement area is considered spatial. It needs to be inspected in locations evenly spread roughly in $200 \mathrm{ft}$ $(60 \mathrm{~m})$ increments, $20 \mathrm{ft}(6 \mathrm{~m})$ on left and right along the RWY or TWY centreline (see Fig. 4).

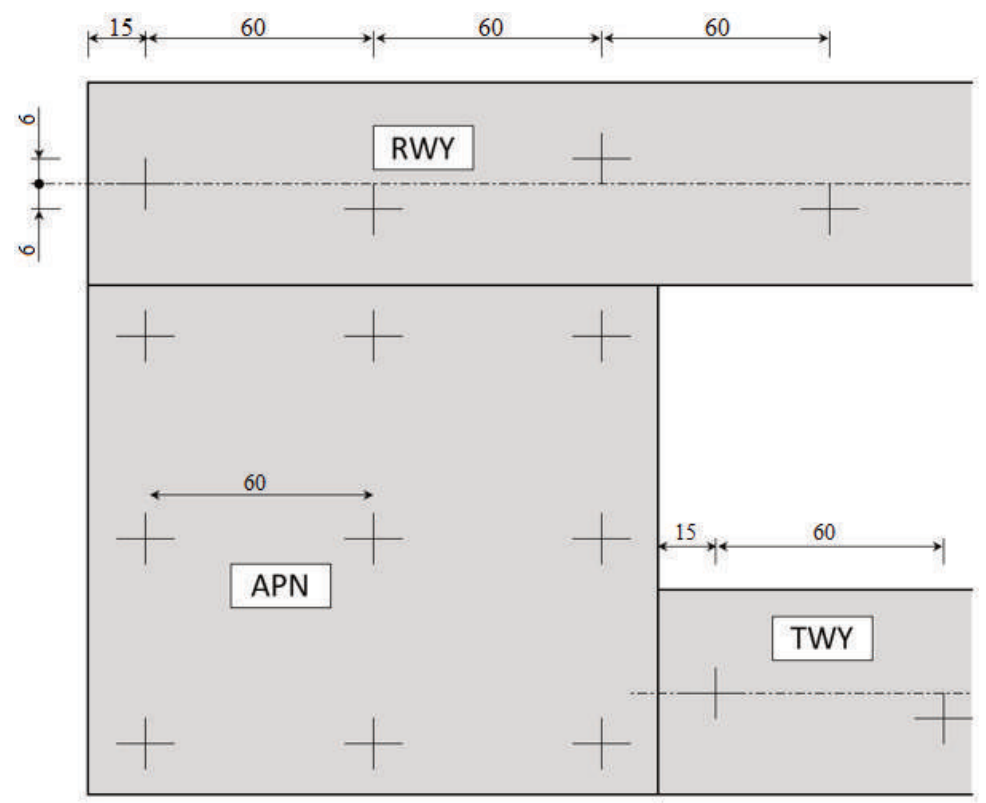

Fig. 4 Measurement locations over a movement area according to the Field Manual [13]

Considering three measurements at each location, all told up to 40 measuring points are needed at an ordinary unpaved airfield with an RWY of $1000 \mathrm{~m}$ in length, one single APN, and TWY [13]. From the hands-on experience, every measurement takes from $10 \mathrm{~min}$ to $15 \mathrm{~min}$ depending on local conditions. When the measured time is multiplied by the actual number of locations, the total time required is between $6 \mathrm{~h}$ 
to $10 \mathrm{~h}$ of intensive and laborious work. Notwithstanding, an additional one or two hours are essential for the collaboration with the results. On top of this, personnel consisting of two are vital in operating the device safely. Not only does the personnel have to have experience in the device operation, but it also has to be well concentrated on work to be done thoroughly well. Even the smallest deviations in a pre-set number of blows may create an error worth considering. With regards to the training, the person is supposed to have some previous practical measuring experience or theoretical knowledge of the device employment, and soil mechanic fundaments. Finally, the entire bearing strength assessment process could be ratified by automation or an implied procedure to a specific airfield condition.

In short, this chapter deals with the DCP application for bearing strength measurements at a specific airport, and its highs and lows. It emphasizes the need to refine the DCP procedure for particular conditions in contrast to a rather general procedure. These might be highly obstructive and therefore extremely unfavourable in already time-constrained airfield operations.

\section{Results}

\subsection{Refinement of Dynamic Cone Penetrometer Methodology for Airport Applications}

As mentioned above, not only is the original methodology of the DCP application highly complicated, but it also does not come with the needs of operational measurements. To tackle both, automation is applied, whether by the development of a simple processing unit built in the device scales, calculating the strength on the spot, or by the development of a pre-mounted matrix for specific conditions at an airfield containing results for a number of blows down to $10 \mathrm{~cm}$ and $30 \mathrm{~cm}$. The first approach shows quite reliable results, but it still requires some elaboration. It comprises data processing which takes place more often in a support area than in the field. On the other hand, the second approach by the matrix use seems to be shaped well for the field application by its simplicity and fast deployment. However, this is earned by lowered accuracy.

The idea of the matrix building should cover the examination of both a model supporting the basic principles of the FM and the procedure for the ADP use conducted at the Air Forces. It should be efficiently launched in the field lacking specific concentration or specialized training to operate. In order to investigate the accuracy, the results are to be compared one from the other and verified with the results gained by the original methodology.

\subsection{Model Based on the Airfield Dynamic Penetrometer Application}

Chiefly, the model based on the experiment according to the ADP application is represented by two formulas giving the strength properties in a number of blows down to the depths of $10 \mathrm{~cm}$ and $30 \mathrm{~cm}$ for the universal conditions representing the prevailing conditions and applied at all airports in the country (see Eqs 1 and 2) [14]. So as to tackle field application requiring a quick evaluation, the results for the entire strength interval with sufficient increments are fitted into a matrix (see Tab. 1). As the number of blows down to $10 \mathrm{~cm}$ and $30 \mathrm{~cm}$ is known, the actual bearing strength value can be derived from the table. 


$$
\begin{aligned}
& n_{10 D C P}=1.67 n_{10 A D P} \\
& n_{30 D C P}=2.26 n_{30 A D P}
\end{aligned}
$$

The table application for the specific soil condition is possible, but it proved to be unnecessary. It creates more errors than additional precision. The reason for this is the occurrence of varying soil conditions even within a single soil profile. If it were feasible, this would require a different formula for each layer. Therefore, an optimized average formula proved to be rational and reasonable enough to represent prevailing soil compositions. As the count of blows is obtained down to the depths of 10 and $30 \mathrm{~cm}$, a regular average is calculated to give the total strength per location. In order to display the idea and the results, a matrix was developed (see Tab. 1). The CBR values in the table are within the required interval applicable for field tests at airfields.

\begin{tabular}{|c|c|c|c|c|c|c|c|c|c|c|c|c|c|c|}
\hline & \multicolumn{12}{|c|}{ Number of blows down to the depth of $10 \mathrm{~cm}$ (1) } \\
\hline & & & 1 & 1.5 & 2 & 2.5 & 3 & 4 & 5 & 6 & 7 & 8 & 9 & 10 \\
\hline & & & \multicolumn{12}{|c|}{ Bearing strength in CBR (\%) } \\
\hline \multirow{4}{*}{$\begin{array}{l}\text { స్ } \\
\text { క } \\
\text { లి }\end{array}$} & 8 & \multirow{4}{*}{$\frac{1}{2}$} & 1.5 & 1.8 & 2.0 & 2.3 & 2.6 & 3.2 & 3.9 & 4.5 & 5.2 & 5.9 & 6.6 & 7.2 \\
\hline & 9 & & 1.6 & 1.9 & 2.2 & 2.5 & 2.8 & 3.4 & 4.0 & 4.7 & 5.3 & 6.0 & 6.7 & 7.4 \\
\hline & 12 & & 2.1 & 2.3 & 2.6 & 2.9 & 3.2 & 3.8 & 4.5 & 5.1 & 5.8 & 6.4 & 7.1 & 7.8 \\
\hline & 14 & & 2.4 & 2.6 & 2.9 & 3.2 & 3.5 & 4.1 & 4.8 & 5.4 & 6.1 & 6.7 & 7.4 & 8.1 \\
\hline & 16 & \multirow{2}{*}{$\frac{6}{8}$} & 2.7 & 2.9 & 3.2 & 3.5 & 3.8 & 4.4 & 5.1 & 5.7 & 6.4 & 7.1 & 7.7 & 8.4 \\
\hline है & 18 & & 3.0 & 3.3 & 3.5 & 3.8 & 4.1 & 4.7 & 5.4 & 6.0 & 6.7 & 7.4 & 8.0 & 8.7 \\
\hline 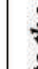 & \multirow{2}{*}{\multicolumn{2}{|c|}{$\frac{20}{22}$}} & 3.3 & 3.6 & 3.8 & 4.1 & 4.4 & 5.1 & 5.7 & 6.3 & 7.0 & 7.7 & 8.4 & 9.1 \\
\hline \multirow{3}{*}{$\frac{8}{2}$} & & & 3.6 & 3.9 & 4.2 & 4.5 & 4.8 & 5.4 & 6.0 & 6.7 & 7.3 & 8.0 & 8.7 & 9.4 \\
\hline & \multicolumn{2}{|c|}{\begin{tabular}{|l|}
24 \\
26
\end{tabular}} & 3.9 & 4.2 & 4.5 & 4.8 & 5.1 & 5.7 & 6.3 & 7.0 & 7.6 & 8.3 & 9.0 & 9.7 \\
\hline & 26 & 20 & 4.3 & 4.5 & 4.8 & 5.1 & 5.4 & 6.0 & 6.7 & 7.3 & 8.0 & 8.6 & 9.3 & 10.0 \\
\hline \multirow{5}{*}{ 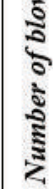 } & 28 & \multirow{2}{*}{ का } & 4.6 & 4.9 & 5.1 & 5.4 & 5.7 & 6.3 & 7.0 & 7.6 & 8.3 & 9.0 & 9.7 & 10.3 \\
\hline & 30 & & 4.9 & 5.2 & 5.5 & 5.8 & 6.1 & 6.7 & 7.3 & 8.0 & 8.6 & 9.3 & 10.0 & 10.7 \\
\hline & 35 & & 5.8 & 6.0 & 6.3 & 6.6 & 6.9 & 7.5 & 8.2 & 8.8 & 9.5 & 10.1 & 10.8 & 11.5 \\
\hline & 40 & & 6.6 & 6.9 & 7.2 & 7.5 & 7.8 & 8.4 & 9.0 & 9.7 & 10.3 & 11.0 & 11.7 & 12.4 \\
\hline & 45 & & 7.5 & 7.7 & 8.0 & 8.3 & 8.6 & 9.2 & 9.9 & 10.5 & 11.2 & 11.9 & 12.5 & 13.2 \\
\hline
\end{tabular}

Tab.1 Fast bearing strength evaluation with the use of the ADP [14]

\subsection{Model Based on the Field Manual}

Considering a model based on the Field Manual developed by the U.S. Corps of Engineers, and respecting the same inputs as the already mentioned case, numbers of blows down to the depths of $10 \mathrm{~cm}$ and $30 \mathrm{~cm}$ can deal with three specific conditions. They comprise the gradual increase in the soil strength over a soil profile, the soft layer over the hard one, and the hard layer over the soft one. Only the condition with varying soil strength properties is not included in the model. It was found rare to known airfield areas. If any doubts about the hard layer present over the soft layer, the original methodology is vital to be launched. The model outcomes can be easily formalized into the table, which is reasonably practical for prompt deployment in the field. Tab. 2 displays the results from the model based on the Field Manual with two inputs, the number of blows down to the depths of $10 \mathrm{~cm}$ and $30 \mathrm{~cm}$ and one output, the bearing strength in the CBR estimate. The varying colours represent three specific conditions. The middle green section intersecting the entire table displays a relatively smooth strength increase with the depth within a soil profile, whereas two extremes, the left bottom blue 
and the right upper red showing the specific conditions with the hard layer over the soft one and the soft layer over the hard one.

Tab. 2 Fast field strength evaluation based on a number of blows down to the depths of $10 \mathrm{~cm}$ and $30 \mathrm{~cm}$, respecting the field manual

\begin{tabular}{|c|c|c|c|c|c|c|c|c|c|c|c|c|c|c|c|c|c|c|c|c|c|}
\hline \multirow{2}{*}{\multicolumn{2}{|c|}{$\begin{array}{l}\text { Number of } \\
\text { blows (CBR) }\end{array}$}} & \multicolumn{20}{|c|}{ Down to the depth of $10 \mathrm{~cm}(1)$} \\
\hline & & 0.5 & $I$ & 1.5 & 2 & 2.5 & 3 & 4 & 5 & $\sigma$ & 7 & 8 & 9 & 10 & 11 & 12 & 14 & 16 & 18 & 20 & 22 \\
\hline \multirow{24}{*}{ 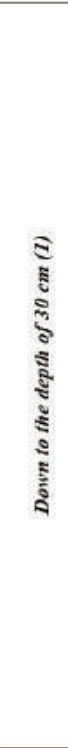 } & 5 & 1.4 & 1.4 & 1.4 & 1.4 & 1.4 & 0.8 & 0.8 & & & & & & & & & & & & & \\
\hline & $\sigma$ & 1.7 & 1.7 & 1.7 & 1.7 & 1.7 & 1.7 & 0.8 & 0.8 & & & & & & & & & & & & \\
\hline & 7 & 2 & 2 & 2 & 2 & 2 & 2 & 1,2 & 0.8 & 0.8 & & & & & & & & & & & \\
\hline & 8 & 2.3 & 2.3 & 2.3 & 2.3 & 2.3 & 2.3 & 2.3 & 1.2 & 1.2 & 1.2 & & & & & & & & & & \\
\hline & 0 & 2.6 & 2.6 & 2.6 & 2.6 & 2.6 & 2.6 & 2.6 & 1.7 & 1.2 & 1.2 & 1.2 & & & & & & & & & \\
\hline & 10 & 3 & 3. & 3 & 3 & 3 & 3 & 3 & 3 & 1.7 & 1.2 & 1.2 & 1.2 & & & & & & & & \\
\hline & 11 & 3.3 & 3.3 & 3.3 & 3.3 & 3.3 & 3.3 & 3.3 & 3.3 & 2.2 & 1.7 & 1.7 & 1.7 & 1.7 & & & & & & & \\
\hline & 12 & 3.7 & 3.7 & 3.7 & 3.7 & 3.7 & 3.7 & 3.7 & 3.7 & 3.7 & 2.2 & 1.7 & 1.7 & 1.7 & 0.4 & & & & & & \\
\hline & 14 & 4.3 & 4.3 & 4.3 & 4.3 & 4.3 & 4.3 & 4.3 & 4.3 & 4.3 & 4.3 & 2.6 & 2.2 & 2.2 & 1.2 & 0.8 & & & & & \\
\hline & 16 & 5 & 5 & 5 & 5 & 5 & 5 & 5 & 5 & 5 & 5 & 5 & 3.1 & 2.6 & 2.2 & 1.7 & 0.8 & & & & \\
\hline & 18 & 5.8 & 5.8 & 5.8 & 5.8 & 5.8 & 5.8 & 5.8 & 5.8 & 5.8 & 5.8 & \begin{tabular}{|l|}
5.8 \\
\end{tabular} & 5.8 & 3.7 & 3.1 & 2.6 & 1.7 & 0.8 & & & \\
\hline & 20 & 6.5 & 6.5 & 6.5 & 6.5 & 6.5 & 6.5 & 6.5 & 6.5 & 6.5 & 6.5 & \begin{tabular}{|l|}
6.5 \\
\end{tabular} & 6.5 & 6.5 & 4.2 & 3.7 & 2.6 & 1.7 & 0.8 & & \\
\hline & 22 & 7.2 & 7.2 & 7.2 & 7.2 & 7.2 & 7.2 & 7.2 & 7.2 & 7.2 & 7.2 & 7.2 & 7.2 & 7.2 & 7.2 & 4.7 & 3.7 & 2.6 & 1.7 & 0.8 & \\
\hline & 24 & 7.9 & 7.9 & 7.9 & 7.9 & 7.9 & 7.9 & 7,9 & 7.9 & 7.9 & 7.9 & \begin{tabular}{|l|}
7.9 \\
\end{tabular} & 7,9 & 7.9 & 7.9 & 7.9 & 4.7 & 3.7 & 2.6 & 1.7 & 0.8 \\
\hline & 26 & 8.7 & 8.7 & 8.7 & 8.7 & 8.7 & 8.7 & 8.7 & 8.7 & 8.7 & 8.7 & \begin{tabular}{|l|}
8.7 \\
\end{tabular} & 8.7 & 8.7 & 8.7 & \begin{tabular}{l|l}
8.7 \\
\end{tabular} & 5.8 & 4.7 & 3.7 & 2.6 & 1.7 \\
\hline & 28 & 9.4 & 9.4 & 9.4 & 9.4 & 9.4 & 9.4 & 9,4 & 9.4 & 9,4 & 9.4 & \begin{tabular}{|l|}
9.4 \\
\end{tabular} & 9.4 & 9.4 & 9.4 & 9.4 & 9.4 & 5.8 & 4.7 & 3.7 & 2.6 \\
\hline & 30 & 10.2 & 10.2 & 10.2 & 10.2 & 10.2 & 10.2 & 10.2 & 10.2 & 10.2 & 10.2 & 10.2 & 10.2 & 10.2 & 10.2 & 10.2 & 10.2 & 6.8 & 5.8 & 4.7 & 3.7 \\
\hline & 35 & 12.1 & 12.1 & 12.1 & 12.1 & 12.1 & 12.1 & 12.1 & 12.1 & 12.1 & 12.1 & 12.1 & 12.1 & 12.1 & 12.1 & 12.1 & 12.1 & 12.1 & 8.5 & 7.4 & 6.3 \\
\hline & 40 & 14.1 & 14.1 & 14.1 & 14.1 & 14.1 & 14.1 & 14.1 & 14.1 & 14.1 & 14.1 & 14.1 & 14.1 & 14.1 & 14.1 & 14.1 & 14.1 & 14.1 & 14.1 & 14.1 & 9.1 \\
\hline & 45 & 16 & 16 & 16 & 16 & 16 & 16 & 16 & 16 & 16 & 16 & 16 & 16 & 16 & 16 & 16 & 16 & 16 & 16 & 16 & 16 \\
\hline & 50 & 18.1 & 18.1 & 18.1 & 18.1 & 18.1 & 18.1 & 18.1 & 18.1 & 18.1 & 18.1 & 18.1 & 18.1 & 18.1 & 18.1 & 18.1 & 18.1 & 18.1 & 18.1 & 18.1 & 18.1 \\
\hline & 55 & 20.1 & 20.1 & 20.1 & 20.1 & 20.1 & 20.1 & 20.1 & 20.1 & 20.1 & 20.1 & 20.1 & 20.1 & 20.1 & 20.1 & 20.1 & 20.1 & 20.1 & 20.1 & 20.1 & 20.1 \\
\hline & 60 & 22.2 & 22.2 & 22.2 & 22.2 & 22.2 & 22.2 & 22.2 & 22.2 & 22.2 & 22.2 & 22.2 & 22.2 & 22.2 & 22.2 & 22.2 & 22.2 & 22.2 & 22.2 & 22.2 & 22.2 \\
\hline & 65 & 24.2 & 24.2 & 24.2 & 24.2 & 24.2 & 24.2 & 24.2 & 24.2 & 24.2 & 24.2 & 24.2 & 24.2 & 24.2 & 24.2 & 24.2 & 24.2 & 24.2 & 24.2 & 24.2 & 24.2 \\
\hline
\end{tabular}

Having worked predominantly with output and input values, which were highly subjective to various conditions, the model was considered to be designed with fuzzy logic help. With regards to fuzzy implications, the Sugeno was successfully tested (see Fig. 5). To create the implications, neuro-adaptive learning through ANFIS (adaptive neuro-fuzzy inference system) toolbox in MATLAB was applied.

By and large, the FM was successfully included in the model with two inputs. Both represent strength properties of a soil profile down to $10 \mathrm{~cm}$ and $30 \mathrm{~cm}$. In order to address time restrictions, the model was formalized into the table serving to bring down the time required in the field.

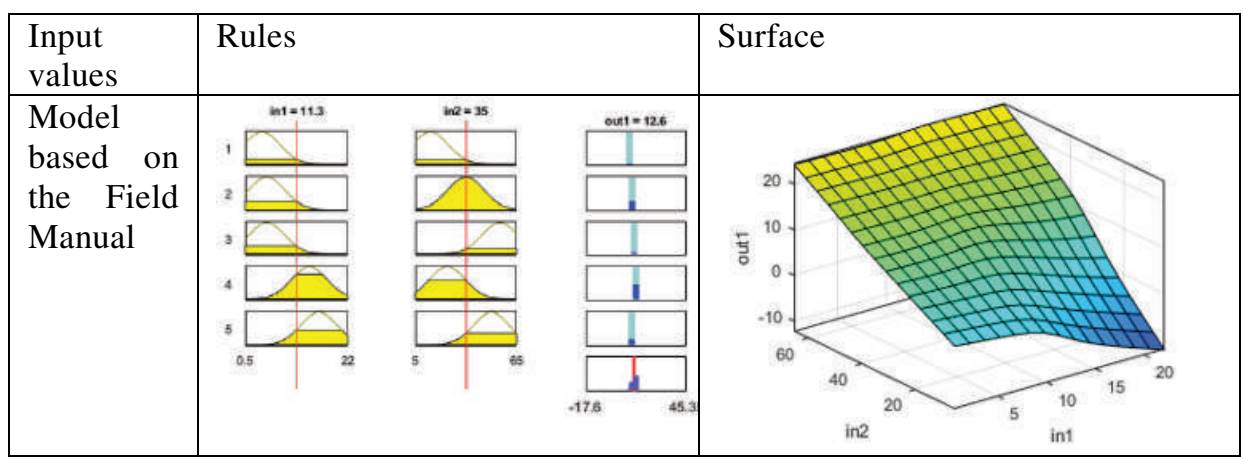

Fig. 5 Fuzzy model for the adopted ADP and the Field Manual methodology 


\subsection{Validation of Applied Models}

The models were tested and compared with a large data sample taken from four airports for the past four years. The data comprised daily operational measurements, as well as measurements conducted during annual spring inspections. The daily measurements are launched at two reference points at an airfield to issue an actual surface condition, whereas the spring inspection measurements are conducted at 36 locations on average. They are more or less aimed at overall surface conditions. Both unpaved transition surfaces to a paved runway and unpaved runways are evaluated.

Firstly, the evaluation via the proposed table arranged with the ADP aid, the methodology proved to be applicable, and the average de-facto measurement uncertainty reached up to $5.3 \%$ (see Fig. 6).

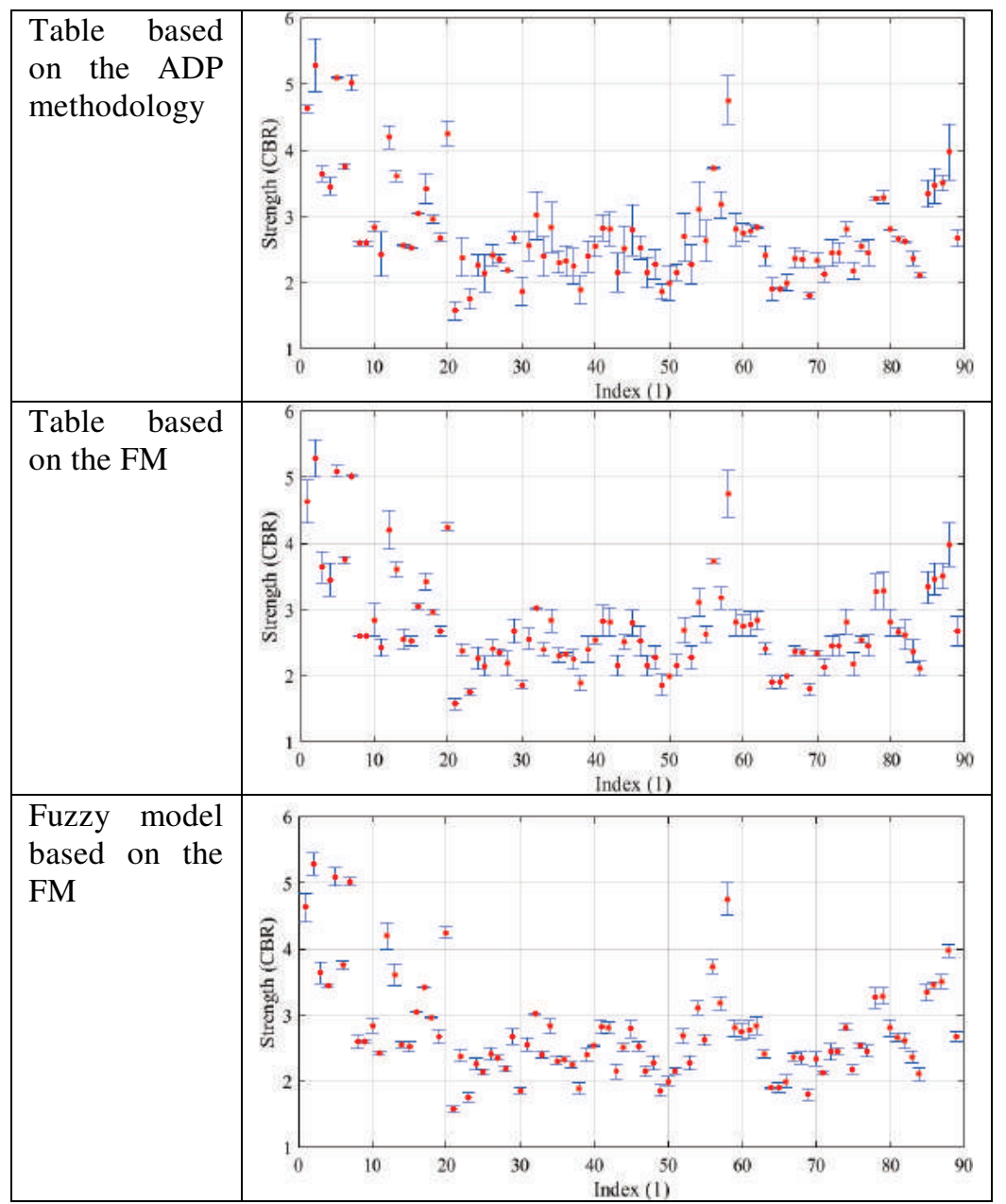

Fig. 6 A sample of the model absolute error

It can be assumed that a systematic uncertainty causes the majority of inaccuracies. That is because the number of blows is rounded while a value is derived from the table. The uncertainty is not typically constant. It preferably fluctuates in the full 
strength interval. On account of this, it cannot be easily formalized. However, having examined the entire table, the likely error was mostly in the margins between $0 \%$ and $16 \%$. Such accuracy should be worth considering.

Secondly, the average uncertainty reached $6.7 \%$ for the table mounted with the table based on the FM (see Fig. 6). Similarly, as mentioned in the previous case, it can be assumed that the systematic uncertainty caused by rounding should explain it. Nevertheless, the uncertainty level is highly dependent upon the soil strength. Typically, the higher strength interval shows relatively acceptable inaccuracy margins from 0 to $6 \%$. On the other hand, the lowest strength values reaching unacceptable levels are extremely inaccurate.

Finally, the model based on the FM and arranged with fuzzy logic aid exhibited considerably high accuracy. The average error reached just $1.35 \%$ (see Fig. 6). The reason for this might be the model continuity in the full strength interval, which was designed for 0 to $24 \mathrm{CBR}$. Although some uncertainties on a few separate exceptional occasions almost reached $8 \%$, the model might be anticipated as a reasonable success. To sum up, as shown in the paragraph, the model based on fuzzy logic is practically applicable with sufficient accuracy. Whereas both tables, whether based on the FM or ADP methodology, have a reasonably high inaccuracy caused by the table application. Nevertheless, since seeking a quickly deployable, low-cost method, the DCP application, primarily incorporating the table based on the FM, can be recommended.

\section{Discussion: Assessment of Practical Application}

Firstly, the refined methodology can preserve a great deal of time required for the operation. That is particularly important in daily airfield operations. In other words, the time required and estimated for the DCP operation application per site has shrunk from the former $15 \mathrm{~min}$ to $5 \mathrm{~min}$ on average. The reason for this is a single-man action, which requires counting numbers of blows down to $10 \mathrm{~cm}$ and $30 \mathrm{~cm}$. Looking at 10 min time savings, it is not much. But considering a large-scale operation, the time savings are enormous. In total, it requires to dedicate just two and half hours of work in contrast to seven and half hours when the original full-scale methodology is followed.

Secondly, device handling can be optimized as well. Since the methodology requires pushing the penetrometer down to the depth of $30 \mathrm{~cm}$ instead of 812.8 , the device length can be reduced to $1.4 \mathrm{~m}$ from roughly $2 \mathrm{~m}$ of the original. That is to say, the convenient connection rod $1 \mathrm{~m}$ long may be optimized to $0.3 \mathrm{~m}$ only. For the sake of this, not only is the device easy to operate, but also the transport in personal vehicles can be without unnecessary device disassembly.

In short, the proposed changes in methodology address the required time savings and obstructive device handling.

\section{Conclusion}

In closing, as shown in the paper, air traffic at airports is an issue these days. Specifically, the majority of accidents at airports involve aircraft running off a movement area. Providing the number of excursions or their causes cannot be eliminated, the outcomes can be effectively mitigated through the proper design, continuous and thorough maintenance of unpaved transition areas to the paved. In order to do so, effective inspection procedures, comprising particularly oversight over the bearing strength, 
have to be well designed to come with the needs of airfield maintenance. In other words, the methodology should be easy to handle, fast enough, and ensuring results with sufficient accuracy. It is feasible to use the DCP set, which has proven to be an extremely efficient tool in building practice. However, although the methodology is adapted to airfield practice, it proved to be too complicated for daily operations. Therefore, the paper proposes a possible methodology refinement to the specific airport conditions. It introduces a model based on fuzzy logic respecting the rules issued by the FM. In order to tackle the field practice, and therefore fast deployment, two tables were proposed and tested upon the values evaluated with the original methodology. The ADP table average de-facto measurement uncertainty reached up to $5.3 \%$. However, some happened to be in the interval between 0 and $16 \%$.

Likewise, the FM-based table displayed an average error of $6.7 \%$. But the uncertainty for the lower strengths reached unacceptable levels. Due to the fact that the table's higher strength interval is vital for practical applications, the table mounted with the aid of the original methodology can be proposed as a substitutive, quick deployable technique for daily inspections at airfields. The FM-based model fixed with fuzzy logic reached an average error of $1.35 \%$. The extremes reached $6 \%$ for the lower strength interval.

\section{Acknowledgement}

The work presented in this paper has been also supported by the Czech Republic Ministry of Defence - University of Defence development program "Support of the Czech Air Force in the local conflicts".

\section{References}

[1] ES, G.W.H. van. A Study of Runway Excursions from a European Perspective. [online]. May 2010. [viewed 2019-06-28]. Available from: https://skybrary. aero/bookshelf/books/2069.pdf

[2] CICMANEC, L. and V. MAREK. Bearing Strength of Unpaved Airport Surfaces Optimization of Number of Measurements. In: Proceedings of the $7^{\text {th }}$ International Conference on Military Technologies, ICMT'19. Brno: University of Defence, 2019, pp. 1-6. DOI 10.1109/MILTECHS.2019.8870107.

[3] Annex 14 -Aerodromes - Volume I-Aerodromes Design and Operations. $8^{\text {th }}$ ed. Montreal: International Civil Aviation Organization, 2018.

[4] Airport Services Manual: Part 2: Pavement Surface Condition. $4^{\text {th }}$ ed. International Civil Aviation Organization, 2002.

[5] RANIERI, V., N. BERloCO, D. D'AURIA, V. DISALVO, V. FEDELE, P. INTINI and P. COLONNA. Determination of Bearing Capacity of Cleared and Graded Areas at Airports. Journal of Transportation Engineering, Part B: Pavements, 2021, 147(1), 04020086. DOI 10.1061/JPEODX.0000247.

[6] CICMANEC, L., J. SAFRANKO and M. PETRASEK. Application of Altered Methodology for Bearing Strength Measurements of Unpaved Airport Surfaces. In: Proceedings of the 22 $2^{\text {nd }}$ International Scientific Conference Transport Means 2018. Kaunas: Kaunas University of Technology, 2018, pp. 336-341. ISSN 1822-296X. 
[7] WEBSTER, S.L., R.W. BROWN and R.W. WILLIAMS. Description and Application of Dual Mass Dynamic Cone Penetrometer [online]. Washington: Department of the Army. May 1992. [viewed 2019-05-03]. Available from: https://erdc-library.erdc.dren.mil/jspui/bitstream/11681/21565/1/IR\%20GL-92-3.pdf

[8] WEINTRAUB, D. Development of an Automated Airfield Dynamic Cone Penetrometer (AADCP) Prototype and the Evaluation of Unsurfaced Airfield Seismic Surveying Using Spectral Analysis of Surface Waves (SASW) Technology [PhD Thesis] [online]. Gainesville: University of Florida, 1993. Available from: https://apps.dtic.mil/sti/pdfs/ADA281985.pdf

[9] ASTM D6951/D6951M-09, Standard Test Method for Use of the Dynamic Cone Penetrometer in Shallow Pavement Applications. West Conshohocken: ASTM International, 2009. DOI 10.1520/D6951_D6951M-18.

[10] SCALA, A.J. Simple Methods of Flexible Pavement Design Using Cone Penetrometers. New Zealand Engineering, 1956, 11(2), pp. 34-44. ISSN 0028-808X.

[11] ZABIELSKA-ADAMSKA, K. and M. SULEWSKA. Dynamic CBR Test to Assess the Soil Compaction. Journal of Testing and Evaluation, 2015, 43(5), pp. 1028-1036. DOI 10.1520/JTE20130256.

[12] HASAN, M.M., M.R. ISLAM and R.A. TAREFDER. Correlating Dynamic Cone Penetrometer and Laboratory Resilient Modulus of Subgrade. In: Proceedings of the $8^{\text {th }}$ International Conference on Maintenance and Rehabilitation of Pavements. Singapore: Research Publishing, 2016. ISBN 978-9-81-110449-7.

[13] Planning and Design of Roads, Airfields, and Heliports in the Theater of Operations-Airfield and Heliport Design: Field Manual No. 5-430-00-2/AFJPAM 328013, Vol. II. Scotts Valley: CreateSpace Independent Publishing Platform, 2013. ISBN 978-1-48-197203-1.

[14] CICMANEC, L. and D. PETRASEK. Runway Excursions: Bearing Strength Measurement Concerns. In: Proceedings of the 2019 IEEE/AIAA $38^{\text {th }}$ Digital Avionics Systems Conference. San Diego: IEEE, 2019. DOI 10.1109/DASC 43569.2019.9081754. 